\title{
Mutational Spectrum of the Succinate Semialdehyde Dehydrogenase (ALDH5A1) Gene and Functional Analysis of 27 Novel Disease-Causing Mutations in Patients With SSADH Deficiency
}

\author{
Shinjiro Akaboshi, ${ }^{1,2}$ Boris M. Hogema, ${ }^{1,3,4}$ Andrea Novelletto, ${ }^{5}$ Patrizia Malaspina, ${ }^{6}$ Gajja S. Salomons, ${ }^{3}$ \\ George D. Maropoulos, ${ }^{7}$ Cornelis Jakobs, ${ }^{3}$ Markus Grompe, ${ }^{1}$ and K. Michael Gibson ${ }^{1 *}$ \\ ${ }^{1}$ Departments of Molecular and Medical Genetics and Pediatrics, Oregon Health and Science University, Portland, Oregon; ${ }^{2}$ Division of Child \\ Neurology, Institute of Neurological Sciences, Tottori University, Tottori, Japan; ${ }^{3}$ Metabolic Unit, Department of Clinical Chemistry, VU \\ University Medical Center, Amsterdam, The Netherlands; ${ }^{4}$ Department of Biochemistry, Erasmus University Medical Center Rotterdam, the \\ Netherlands; ${ }^{5}$ Department of Cell Biology, University of Calabria, Rende, Italy; ${ }^{6}$ Department of Biology, "Tor Vergata" University of Rome, Rome, \\ Italy; ${ }^{7}$ Department of Biochemistry, General Hospital of Athens, 'Laiko,' Greece
}

Communicated by Johannes Zschocke

\begin{abstract}
Succinate semialdehyde dehydrogenase (SSADH; ALDH5A1) deficiency, a rare metabolic disorder that disrupts the normal degradation of GABA, gives rise to a highly heterogeneous neurological phenotype ranging from mild to very severe. The nature of the mutation has so far been reported in patients from six families world wide and eight different mutations were described. Here we report the mutational spectrum in 48 additional unrelated families of different geographic origin. We detected 27 novel mutations at the cDNA level, of which 26 could be attributed to changes at the genomic level. Furthermore, six mutations were detected that did not strongly affect SSADH activity when expressed in HEK 293 cells and are considered nonpathogenic allelic variants. Twenty of the mutations were only found in one family. The spectrum of disease-causing mutations from all patients sequenced thus far consists of 25 point mutations, four small insertions, and five small deletions. Seven of these mutations affect splice junctions, seven are nonsense mutations, and 12 are missense mutations. Although there were no mutational hotspots or prevalent mutations responsible for a significant number of cases, 14 out of $37(38 \%)$ of the missense alleles were present in exon 4 or 5 . With one exception, the missense mutations we consider to be causative of SSADH deficiency reduced the SSADH activity to less than $5 \%$ of the normal activity in our in vitro expression system. This indicates that residual expression is not likely to be an important factor contributing to the large phenotypic differences observed among different families and even among siblings, suggesting that other modifying factors are of great importance in disease pathology. Hum Mutat 22:442-450, 2003. (c) 2003 Wiley-Liss, Inc.
\end{abstract}

KEY wORDS: succinate semialdehyde; GABA metabolism; aldehyde dehydrogenases; GHB; ALDH5A1; SSADH

DATABASES:

ALDH5A1 - OMIM: 271980; GenBank: AL031230 (genomic), Y11192 (cDNA)

\section{INTRODUCTION}

Deficiency of succinate semialdehyde dehydrogenase (SSADH; ALDH5A1; EC 1.2.1.24; MIM\# 271980) is a rare autosomal recessively inherited metabolic disorder that results in accumulation of 4-hydroxybutyrate (GHB; Fig. 1). GHB possesses a number of unusual neuropharmacologic properties primarily mediated via the dopaminergic system, and is used to treat cataplexy and drugwithdrawal syndromes, to induce absence seizures in animal models, and as a drug of abuse linked to its putative euphoric effects [Mason and Kerns, 2002]. SSADH is a mitochondrial, $\mathrm{NAD}^{+}$-dependent enzyme that catalyzes the oxidation of succinate semialdehyde to
Received 30 January 2003; accepted revised manuscript 24 June 2003.

*Correspondence to: K. Michael Gibson, Ph.D., FACMG, Department of Molecular and Medical Genetics, Biochemical Genetics Laboratory, Oregon Health and Science University, Mail Code MP-350, 2525 SW 3rd Avenue, Suite 350, Portland, OR 97201.

E-mail: gibsonm@ohsu.edu

Grant sponsor: Telethon Onlus Italia; Grant number: E.818; Grant sponsor: NIH; Grant number: NS 40270; Grant sponsor: March of Dimes National Birth Defects Foundation; Grant number: 1-FY00352.

Shinjiro Akaboshi and Boris M. Hogema contributed equally to this work.

DOI 10.1002/humu.10288

Published online inWiley InterScience (www.interscience.wiley.com). 

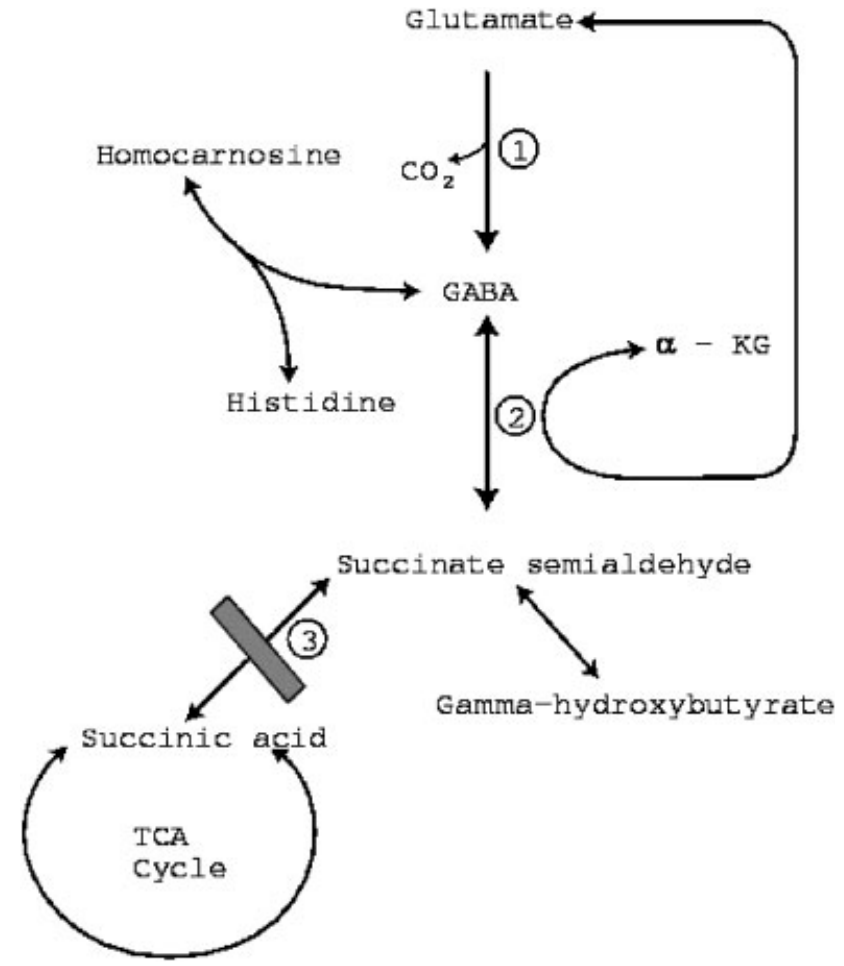

FIGURE 1. The GABA catabolic pathway and GABA "shunt." In CNS tissue, the "shunt" refers to the regeneration of glutamate, the main $\mathrm{GABA}$ precursor, during the transamination reaction which converts GABA to succinic semialdehyde, with stoichiometric production of glutamate from alpha-ketoglutarate. The site of the block in SSADH deficiency is indicated by the solid box. Numbered reactions include: 1 , glutamate decarboxylase; 2, GABA-transaminase; and 3, succinate semialdehyde dehydrogenase. Abbreviations: GABA, 4 -aminobutyric acid; $\alpha$-KG, $\alpha$-ketoglutarate; TCA, tricarboxylic acid.

succinate, which is the second and final step of the 4-aminobutyric acid (GABA) metabolic pathway. GHB is subsequently formed from succinate semialdehyde by one or more NADPH-linked GHB dehydrogenases [Cash et al., 1979] and is likely to be important in disease pathogenesis [Gibson et al., 1998]. The enzyme deficiency also leads to significant accumulation of GABA, which makes SSADH deficiency a unique disorder, since the levels of two neuroactive compounds are increased. Furthermore, it is unusual in the sense that seizures occur in about $50 \%$ of patients even though GABA is increased. Since the description of the first patient [Jakobs et al., 1981] approximately 300 patients have been diagnosed [Gibson and Jakobs, 2001]. The clinical phenotype is highly variable (both interfamilial and intrafamilial) and ranges from mild retardation in language, motor, and mental development to severe neurological defects such as seizures, hypotonia, ataxia, and behavioral problems, especially in older patients [Gibson et al., 1997a]. Although the disease is usually diagnosed during childhood it has been found in adults as well [Jakobs et al., 1990]. EEG and MRI abnormalities have been described in some cases, but proper diagnosis can only be achieved by organic acid analysis of urine or plasma, followed by enzymatic determination of SSADH activity in leukocytes, and recently by DNA sequence analysis [Gibson et al., 1991, 1994; Chambliss et al., 1998; Hogema et al., 2001a; Aoshima et al., 2002].

The ALDH5A1 gene is located on chromosome 6p22 and consists of 10 exons encompassing over $38 \mathrm{~kb}$. The open reading frame consists of $1,605 \mathrm{bp}$, encoding 535 amino acids, of which the first 47 residues form the mitochondrial targeting sequence [Chambliss et al., 1995, 1998; Trettel et al., 1997]. Recently we described the complete genomic structure of the gene and found an alternatively spliced small exon which may encode a novel isoform of the enzyme with an additional 13 amino acids [Blasi et al., 2002].

Eight different pathologic mutations in the ALDH5A1 gene in patients from six different families have been described in the literature [Chambliss et al., 1998; Hogema et al., 2001a; Aoshima et al., 2002]. Mutant in vitro expression has not been performed in these studies, and the possibility that some of the mutations represent nonpathogenic polymorphisms could not be excluded. In order to gain a better understanding of the molecular basis of the disease, we screened the ALDH5A1 coding region in 61 additional patients from 48 different families by sequence analysis of genomic DNA and/or cDNA. (Fig. 2)

\section{Human Subjects \\ MATERIALS AND METHODS}

All patients analyzed for ALDH5A1 mutations in this study were diagnosed by measurement of SSADH activity in leukocytes after detection of abnormal GHB levels in physiological fluids [Gibson et al., 1990, 1994]. In addition, 56 probands' relatives from 22 different families were evaluated for mutations found in probands. In case families were known to be related only one of the patients (or sibships) is represented in our results because we never found additional mutations or polymorphisms in the related families. All samples submitted to analysis were obtained with informed consent of either the patients or the caregivers.

\section{Mutation Screening}

Total RNA and genomic DNA were extracted from lymphoblastoid or epithelial cell lines derived from patients or from fresh lymphocytes or whole blood using standard procedures. RT-PCR was performed using Gibco reverse transcriptase and Taq polymerase according to the instructions of the manufacturer, and in order to improve the low yields caused by the high GCcontent of the $5^{\prime}$ end of the gene, betaine $(1 \mathrm{M})$ was added to the reactions. Even then we could not amplify the first $258 \mathrm{bp}$ of the open reading frame by RT-PCR. For that reason we analyzed the first exon by sequence analysis from genomic PCR products generated using platinum Taq polymerase (Gibco, Grand Island, $\mathrm{NY}$ ) in the presence of $1 \mathrm{M}$ betaine. Other genomic PCR reactions were done using regular Taq polymerase (Gibco), using the PCR primer pairs listed in Table 1. PCR amplification was performed using PCR mixes as specified by the manufacturer. The PCR conditions were: denaturation $94^{\circ} \mathrm{C}$ for $4 \mathrm{~min}$ followed by 30 cycles $\left(94^{\circ} \mathrm{C}\right.$ for $45 \mathrm{sec}$, annealing at $53^{\circ} \mathrm{C}$ for $1 \mathrm{~min}$, extension at $72^{\circ} \mathrm{C}$ for $2 \mathrm{~min}$ ), followed by a further extension at $72^{\circ} \mathrm{C}$ for $5 \mathrm{~min}$. PCR products were purified using the Qiagen PCR cleanup kit and sequenced using BigDye dideoxy terminators (Perkin Elmer, Boston, MA) and an ABI automated sequencer. If two different size bands were detected in RT-PCR reactions, both bands were sequenced to verify which part of the coding region was missing. 


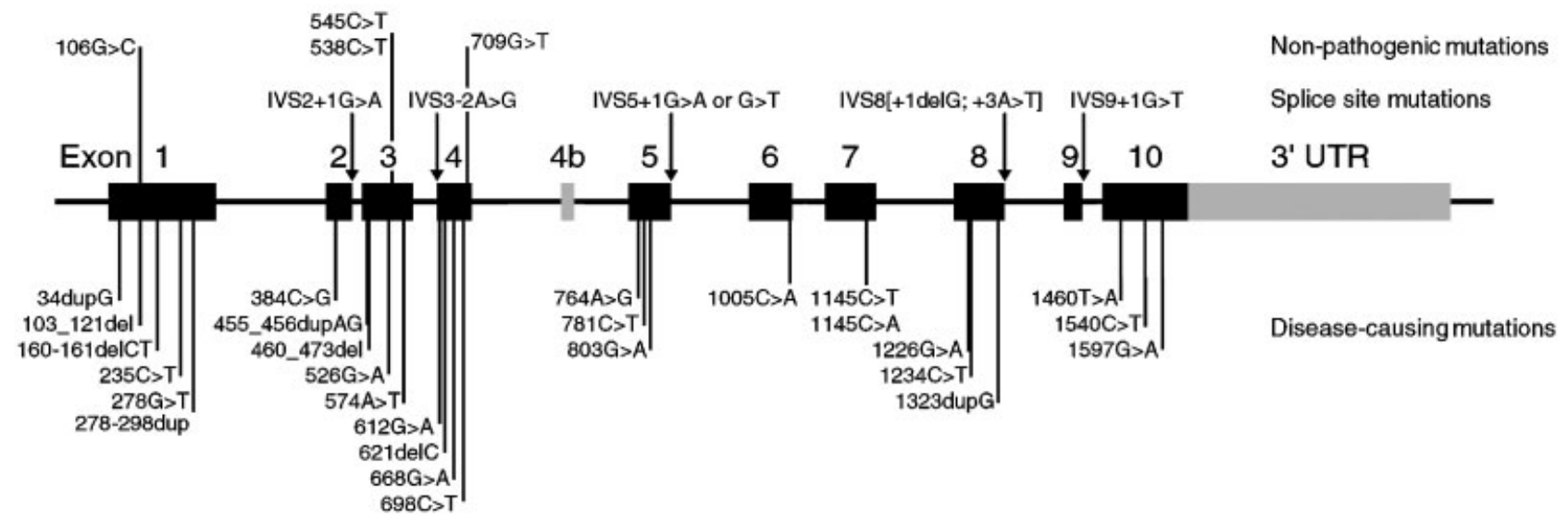

FIGURE 2. Summary of mutations and polymorphisms in ALDH5A1. Splice site mutations and nondeleterious mutations are shown above the diagram of the intron/exon structure and disease-causing mutations are indicated below, all in terms of cDNA sequence. The figure is drawn to scale with the size of the introns reduced to $5 \%$ of the actual length for clarity.

TABLE 1. Primer Pairs Used for Amplifying the ALDH5A1 Coding Regions

\begin{tabular}{|c|c|c|}
\hline Primer name & Primer sequence $\left(5^{\prime}-3^{\prime}\right)$ & $\begin{array}{c}\text { Product } \\
\text { length }(b p)\end{array}$ \\
\hline RT-PCR F & TCTGGGCATGGTAGCCGACTG & 1477 \\
\hline RT-PCR R & GGACTGGATGAGTTCTGAAAAATTC & \\
\hline Exon $1 \mathrm{~F}$ & TGCTCTGTGGCTCTGCAACCTTCCG & 655 \\
\hline Exon $1 \mathrm{R}$ & CCCTTGTTGCTCTGACTTTCCAC & \\
\hline Exon $2 \mathrm{~F}$ & CACGGACATACCCAGAAATGATG & 348 \\
\hline Exon $2 \mathrm{R}$ & GCGGCTTTCCCAAGTTTAGTG & \\
\hline Exon $3 \mathrm{~F}$ & TTTTCCCCACTCTATGGGTATCG & 361 \\
\hline Exon $3 \mathrm{R}$ & TGTTTCCCAACTCCCTATCCAATC & \\
\hline Exon $4 \mathrm{~F}$ & GGTTTGTCAATCAGTTGTGC & 475 \\
\hline Exon $4 \mathrm{R}$ & ATAGATACCATTTACAGTAGG & \\
\hline Exon $4 \mathrm{BF}$ & TGTGACTTCCTTAAATTGGGC & 301 \\
\hline Exon 4B R & AGGGGGAGCTACTACATCA & \\
\hline Exon $5 \mathrm{~F}$ & GTAAATTGTTGGCACATGTTTG & 271 \\
\hline Exon $5 \mathrm{R}$ & TGGTGATCAGGATGAAATAG & \\
\hline Exon $6 \mathrm{~F}$ & CCAGCCTCTTCCCAATGTTTC & 393 \\
\hline Exon $6 \mathrm{R}$ & ACATGCACACGCAAACACACATC & \\
\hline Exon $7 \mathrm{~F}$ & CACCGAGGGAAGTGTTTCAC & 330 \\
\hline Exon $7 \mathrm{R}$ & TGCTGATTAAGCTTTTCATATTG & \\
\hline Exon $8 \mathrm{~F}$ & CTGAATCTCTGCAAATGTGGTTCC & 410 \\
\hline Exon $8 \mathrm{R}$ & CTCTTTCAGGGTTTCCTATG & \\
\hline Exon $9 \mathrm{~F}$ & CTGAGTTATAACGGGGAATGGT & 470 \\
\hline Exon $9 \mathrm{R}$ & TGCACCTTCTCTTCTTCCCACA & \\
\hline Exon $10 \mathrm{~F}$ & TCATCAATGGTGCCCTCATC & 415 \\
\hline Exon $10 \mathrm{R}$ & GGACTGGATGAGTTCTGAAAAATTC & \\
\hline
\end{tabular}

Mutations found in RT-PCR products were always verified by sequencing the corresponding exon amplified from genomic DNA. If no mutation or only one mutated allele was found with the RNA-based method all exons were sequenced.

\section{Nomenclature and Sequence Analysis}

Mutation nomenclature follows the guidelines from den Dunnen and Antonarakis [2000]. Numbering of nucleotide and amino acid positions refers to the complete cDNA sequence (GenBank accession Y11192) including the mitochondrial leader sequence and starting from the first ATG or amino acid. Sequences were aligned using the DNAstar program Megalign and sequence motifs were analyzed using the PFAM and Prosite databases.

\section{Functional Analysis of ALDH5A1 Alleles}

Missense mutations detected in patients were introduced into a pAD1/RSV-driven expression vector described previously [Blasi et al., 2002] using the 'quickchange' site-directed mutagenesis kit (Stratagene, La Jolla, CA) as recommended by the manufacturer.
Resulting mutations were confirmed by sequence analysis. Expression was measured $48 \mathrm{hr}$ after transfection of HEK293 cells with the Effectene transfection reagent (Qiagen, Valencia, CA) by using the fluorometric assay as described [Gibson et al., 1991].

\section{Genotyping}

\section{RESULTS}

The results of sequence analysis of ALDH5A1 cDNA and/or genomic DNA of patients from 54 families that are not known to be related in whom SSADH deficiency was diagnosed are reported in Table 2. This table includes the six families of whom the mutations were previously published [Chambliss et al., 1998; Hogema et al., 2001a; Aoshima et al., 2002]. Only three alleles (in families 19, 25, and 29) could not be attributed to specific mutations at the genomic level, showing that the methods employed by us resulted in a high mutation detection rate $(97 \%)$. In one of these three cases (family 
TABLE 2. Identification of the Mutations and Polymorphisms in ALDH5A1 in 54 Different Families

\begin{tabular}{|c|c|c|c|c|c|c|}
\hline Family no. & Mutation $1^{\mathrm{a}}$ & Mutation 2 & $\begin{array}{c}\text { Genotype } \\
\text { at c.538 }\end{array}$ & $\begin{array}{c}\text { Additional } \\
\text { polymorphisms }\end{array}$ & Ethnic origin & Reference/remarks \\
\hline 1 & c.34dupG & c. $612 \mathrm{G}>\mathrm{A}$ & $\mathrm{C} / \mathrm{C}$ & c. $1216 \mathrm{G}>\mathrm{A}$ & British & \\
\hline 2 & c.103_121del & c. $1460 \mathrm{~T}>\mathrm{A}$ & n.d. ${ }^{b}$ & & Japan & Aoshima et al. [2002] ${ }^{c}$ \\
\hline 3 & c. $235 \mathrm{C}>\mathrm{T}$ & c. $235 \mathrm{C}>\mathrm{T}$ & $\mathrm{T} / \mathrm{T}$ & $\begin{array}{l}\text { c. } 106 \mathrm{G}>\mathrm{C}+ \\
\text { c. } 106 \mathrm{G}>\mathrm{C}+ \\
\text { c. } 545 \mathrm{C}>\mathrm{T}+ \\
\mathrm{c} 545 \mathrm{C}>\mathrm{T}\end{array}$ & New Caledonia & Gibson et al. [1997b] \\
\hline 4 & c.278_298dup & c. $1145 \mathrm{C}>\mathrm{T}$ & $\mathrm{C} / \mathrm{T}$ & & Greek & \\
\hline 5 & c. $278 \mathrm{G}>\mathrm{T}$ & c. $278 \mathrm{G}>\mathrm{T}$ & $\mathrm{C} / \mathrm{C}$ & & Turkey & Jakobs et al. [1981] \\
\hline 6 & c. $278 \mathrm{G}>\mathrm{T}$ & IVS $5+1 G>T$ & $\mathrm{C} / \mathrm{T}$ & & India & Aligianis et al. [2002] \\
\hline 7 & c. $278 \mathrm{G}>\mathrm{T}$ & c. $1597 \mathrm{G}>\mathrm{A}$ & $\mathrm{C} / \mathrm{C}$ & & Unknown & \\
\hline 8 & c. $384 \mathrm{C}>\mathrm{G}$ & c. $384 \mathrm{C}>\mathrm{G}$ & $\mathrm{C} / \mathrm{C}$ & & Inuit & $\begin{array}{l}\text { Gibson et al. [1997a]; } \\
\text { patient P.F. }\end{array}$ \\
\hline 9 & c.455_456dupAG & c.455_456dupAG & $\mathrm{C} / \mathrm{C}$ & & Unknown & \\
\hline 10 & c.460_473del & c. $460 \_473 \mathrm{del}$ & $\mathrm{T} / \mathrm{T}$ & & Hispanic & Gibson et al. [1988] \\
\hline 11 & c. $526 \mathrm{G}>\mathrm{A}$ & c. $526 \mathrm{G}>\mathrm{A}$ & $\mathrm{C} / \mathrm{C}$ & & India & $\begin{array}{l}\text { Gibson et al. [1997a]; } \\
\text { patient P.V. }\end{array}$ \\
\hline 12 & c. $526 \mathrm{G}>\mathrm{A}$ & c.1226G $>A$ & $\mathrm{C} / \mathrm{C}$ & & Greek & \\
\hline 13 & c. $612 \mathrm{G}>\mathrm{A}$ & c. $612 \mathrm{G}>\mathrm{A}$ & $\mathrm{C} / \mathrm{C}$ & & American-European & \\
\hline 14 & c. $612 \mathrm{G}>\mathrm{A}$ & c. $612 \mathrm{G}>\mathrm{A}$ & $\mathrm{C} / \mathrm{C}$ & & Unknown & DeVivo et al. [1988] \\
\hline 15 & c. $612 \mathrm{G}>\mathrm{A}$ & c. $803 \mathrm{G}>\mathrm{A}$ & $\mathrm{C} / \mathrm{T}$ & & American-European & $\begin{array}{l}\text { Hogema et al. [2001a] } \\
612 \mathrm{G}>\text { A not expressed }\end{array}$ \\
\hline 16 & c. $612 \mathrm{G}>\mathrm{A}$ & c. $1005 \mathrm{C}>\mathrm{A}$ & $\mathrm{C} / \mathrm{C}$ & & American-European & $\begin{array}{l}\text { The } 612 \mathrm{G}>\mathrm{A} \text { allele was } \\
\text { not expressed }\end{array}$ \\
\hline 17 & c. $612 \mathrm{G}>\mathrm{A}$ & c. $1234 \mathrm{C}>\mathrm{T}$ & $\mathrm{C} / \mathrm{C}$ & & Australian & Hogema et al. [2001a] ${ }^{c}$ \\
\hline 18 & c. $612 \mathrm{G}>\mathrm{A}$ & c. $1540 \mathrm{C}>\mathrm{T}$ & $\mathrm{C} / \mathrm{C}$ & & American-European & $\begin{array}{l}\text { The } 612 \mathrm{G}>\mathrm{A} \text { allele was } \\
\text { not expressed }\end{array}$ \\
\hline 19 & c. $612 \mathrm{G}>\mathrm{A}$ & $?$ & $\mathrm{C} / \mathrm{T}$ & & French & No RT-PCR product \\
\hline 20 & c.621delC & c.621delC & $\mathrm{C} / \mathrm{C}$ & & Turkey & \\
\hline 21 & c. $668 \mathrm{G}>\mathrm{A}$ & c. $668 \mathrm{G}>\mathrm{A}$ & $\mathrm{C} / \mathrm{C}$ & $\begin{array}{l}\text { c.709G }>\mathrm{T}+ \\
\text { c.709G }>\mathrm{T}\end{array}$ & Unknown & \\
\hline 22 & c. $698 \mathrm{C}>\mathrm{T}$ & c. $698 \mathrm{C}>\mathrm{T}$ & $\mathrm{T} / \mathrm{T}$ & & Turkey & \\
\hline 23 & c. $698 \mathrm{C}>\mathrm{T}$ & c. $698 \mathrm{C}>\mathrm{T}$ & $\mathrm{T} / \mathrm{T}$ & & Turkey & $\begin{array}{l}\text { Gibson et al. [1997a]; } \\
\text { patient K.S. }\end{array}$ \\
\hline 24 & c. $698 \mathrm{C}>\mathrm{T}$ & c. $698 \mathrm{C}>\mathrm{T}$ & $\mathrm{T} / \mathrm{T}$ & & Unknown & $\begin{array}{l}\text { Jakobs et al. [1990]; } \\
\text { no RT-PCR product detected }\end{array}$ \\
\hline 25 & c. $764 A>G$ & $?$ & $\mathrm{C} / \mathrm{T}$ & $\begin{array}{l}\text { c. } 106 \mathrm{G}>\mathrm{C}+ \\
\text { c. } 545 \mathrm{C}>\mathrm{T}\end{array}$ & Lebanese & $\begin{array}{l}\text { Gibson et al. [1997a]; } \\
\text { patientT.A. }\end{array}$ \\
\hline 26 & c. $781 \mathrm{C}>\mathrm{T}$ & c. $803 \mathrm{G}>\mathrm{A}$ & $\mathrm{C} / \mathrm{T}$ & & Swedish & No RT-PCR product detected \\
\hline 27 & c. $803 \mathrm{G}>\mathrm{A}$ & c. $1234 \mathrm{C}>\mathrm{T}$ & $\mathrm{C} / \mathrm{T}$ & & American-European & $\begin{array}{l}\text { Gibson et al. [1989]; } \\
\text { 1234C > T not expressed }\end{array}$ \\
\hline 28 & c.803G $>A$ & c.34dupG & $\mathrm{C} / \mathrm{T}$ & & United Kingdom & $\begin{array}{l}\text { The c. } 34 \text { dupG allele was not } \\
\text { expressed }\end{array}$ \\
\hline 29 & c. $803 \mathrm{G}>\mathrm{A}$ & r.EX2_EX5del & T/L.O.H. ${ }^{d}$ & c. $1389 \mathrm{~T}>\mathrm{C}$ & Swedish & \\
\hline 30 & c. $1145 \mathrm{C}>\mathrm{A}$ & c. $1145 \mathrm{C}>\mathrm{A}$ & $\mathrm{C} / \mathrm{C}$ & & Unknown & \\
\hline 31 & c. $1226 \mathrm{G}>\mathrm{A}$ & c. $1226 \mathrm{G}>\mathrm{A}$ & $\mathrm{C} / \mathrm{C}$ & & Greek & Hogema et al. [2001a] ${ }^{c}$ \\
\hline 32 & c. $1226 \mathrm{G}>\mathrm{A}$ & c.1226G $>A$ & $\mathrm{C} / \mathrm{C}$ & & Dutch & $\begin{array}{l}\text { Gibson et al. [1997a]; } \\
\text { patient E.G. }\end{array}$ \\
\hline 33 & c.1226G $>A$ & c. $1226 \mathrm{G}>\mathrm{A}$ & $\mathrm{C} / \mathrm{C}$ & & Croatian & \\
\hline 34 & c. $1226 \mathrm{G}>\mathrm{A}$ & IVS2 $+1 G>A$ & $\mathrm{C} / \mathrm{T}$ & c. $545 \mathrm{C}>\mathrm{T}$ & Greek & \\
\hline 35 & c. $1234 \mathrm{C}>\mathrm{T}$ & c. $1234 \mathrm{C}>\mathrm{T}$ & $\mathrm{C} / \mathrm{C}$ & & American-European & Hodson et al. [1990] \\
\hline 36 & c. $1234 \mathrm{C}>\mathrm{T}$ & c. $1234 \mathrm{C}>\mathrm{T}$ & $\mathrm{C} / \mathrm{C}$ & & Pakistan & No RT-PCR product detected \\
\hline 37 & c.1234C $>\mathrm{T}$ & c. $1234 \mathrm{C}>\mathrm{T}$ & $\mathrm{C} / \mathrm{C}$ & & American-European & $\begin{array}{l}\text { Gibson et al. [1997a]; } \\
\text { patient M.W. }\end{array}$ \\
\hline 38 & c. $1234 \mathrm{C}>\mathrm{T}$ & c. $1234 \mathrm{C}>\mathrm{T}$ & $\mathrm{C} / \mathrm{C}$ & & Unknown & \\
\hline 39 & c.1323dupG & c.1323dupG & $\mathrm{C} / \mathrm{T}$ & & Dutch & \\
\hline 40 & c. $1540 \mathrm{C}>\mathrm{T}$ & c.160_161delCT & $\mathrm{C} / \mathrm{C}$ & & Unknown & \\
\hline 41 & c. $1540 \mathrm{C}>\mathrm{T}$ & c. $1540 \mathrm{C}>\mathrm{T}$ & $\mathrm{C} / \mathrm{C}$ & & Unknown & \\
\hline 42 & c. $1597 \mathrm{G}>\mathrm{A}$ & c.160_161delCT & $\mathrm{C} / \mathrm{C}$ & & Italian & $\begin{array}{l}\text { The 160_161delCT allele was } \\
\text { not expressed }\end{array}$ \\
\hline 43 & IVS3_2A $>$ G & c. $574 \mathrm{~A}>\mathrm{T}$ & $\mathrm{C} / \mathrm{T}$ & & Nova Scotia & \\
\hline 44 & IVS3_2A $>G$ & c. $1234 \mathrm{C}>\mathrm{T}$ & $\mathrm{C} / \mathrm{C}$ & & American-European & \\
\hline 45 & IVS $5+1 G>A$ & IVS $5+1 G>A$ & $\mathrm{C} / \mathrm{C}$ & & Malta & $\begin{array}{l}\text { Chambliss et al. }[1998]^{c} \text {; } \\
\text { patient A.C. }\end{array}$ \\
\hline 46 & IVS $5+1 G>T$ & IVS $5+1 G>T$ & $\mathbf{T} / \mathrm{T}$ & & Turkey & $\begin{array}{l}\text { Gibson et al. [1997a]; } \\
\text { patientY.A. }\end{array}$ \\
\hline 47 & IVS6-2A $>C$ & c. $1226 \mathrm{G}>\mathrm{A}$ & $\mathrm{C} / \mathrm{T}$ & & Haitan/Spanish & \\
\hline 48 & $\begin{array}{l}\text { IVS8+1delG; } \\
\text { IVS8+3A }>\text { T }\end{array}$ & $\begin{array}{l}\text { IVS8+1delG; } \\
\text { IVS8+3A }>\text { T }\end{array}$ & $\mathrm{C} / \mathrm{C}$ & & Palestinian-Lebanese & $\begin{array}{l}\text { Gibson et al. [1997a]; } \\
\text { patient A.E-M. }\end{array}$ \\
\hline 49 & $\begin{array}{l}\text { IVS8+1delG; } \\
\text { IVS8+3A >T }\end{array}$ & $\begin{array}{l}\text { IVS8+1delG; } \\
\text { IVS8+3A }>\text { T }\end{array}$ & $\mathrm{C} / \mathrm{C}$ & & Pakistan & $\begin{array}{l}\text { Gibson et al. [1997a]; } \\
\text { patient M.S. }\end{array}$ \\
\hline 50 & IVS9+1G $>T$ & IVS $9+1 G>T$ & $\mathrm{~T} / \mathrm{T}$ & & Turkey & $\begin{array}{l}\text { Chambliss et al. }[1998]^{c} \text {; } \\
\text { patient Z.Z. }\end{array}$ \\
\hline 51 & IVS9+1G $>T$ & IVS9+1G $>T$ & $\mathrm{~T} / \mathrm{T}$ & & Turkey & \\
\hline 52 & IVS9 $+1 G>T$ & IVS $9+1 G>T$ & $\mathrm{~T} / \mathrm{T}$ & & Syrian & $\begin{array}{l}\text { Gibson et al. [1997a]; } \\
\text { patient B.H. }\end{array}$ \\
\hline 53 & IVS9+1G $>$ T & IVS9+1G $>\mathrm{T}$ & $\mathrm{T} / \mathrm{T}$ & & Unknown & \\
\hline 54 & IVS9+1G $>T$ & IVS9+1G $>T$ & $\mathrm{~T} / \mathrm{T}$ & & Unknown & \\
\hline
\end{tabular}

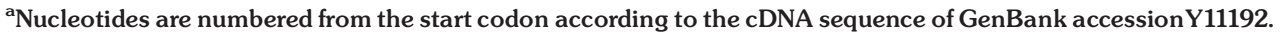

b.d., not determined.

${ }^{\mathrm{c}}$ Mutation analysis in these patient has been reported previously.

${ }^{\mathrm{d}}$ L.O.H.: loss of heterozygosity. 
19), no RT-PCR product was obtained. In the patient from family 29 we found a heterozygous deletion of exons 2-5 in the RT-PCR product, but no mutations were found in the parts of the genomic DNA we sequenced. The complex haplotype of Patient 25 will be discussed later.

The features of all currently known mutations, including the eight mutations found in six different families that have been published previously [Chambliss et al., 1998; Hogema et al., 2001a; Aoshima et al., 2002] are summarized in Table 3. Patients from 23 of the 55 different families were compound heterozygotes and in 32 families patients were homozygous. This probably results from the rather high percentage (approximately $40 \%$ ) of consanguinity in families with SSADH deficiency [Gibson et al., 1997a]. The most common mutation (W204X) was found in eight different families (in 8 out of 10 cases in compound heterozygous patients), all with European ancestry, suggesting a founder effect for this mutation. The second most common mutation (R412X) was detected in seven families (four homozygous patients) from various geographic origins.

Table 3 also shows the patients' genotypes for the common c.538C $>\mathrm{T}$ nucleotide substitution, which results in the H180Y amino acid substitution. The associations of the various mutations and the allele at pos. 538 could be resolved unequivocally with the exception of families 4, 25, 34, and 47. One patient (family 29) showed loss of heterozygosity at pos. 538, due to deletion of exons 2-5 in which this position resides. This patient also carried the c.1389T $>C$ mutation, a silent third-base substitution affecting codon D463.

Six patients showed additional sequence variations, which were not considered causative of SSADH deficiency as shown in Table 2, column 5. It is interesting to see that three of them carried both the G36R $($ c. $106 \mathrm{G}>\mathrm{C})$ and the P182L (c.545C $>$ T) substitutions. The patient of family 3 is homozygous for both substitutions, showing that they were transmitted in cis. This would also be compatible with the genotype of Patients 25 and 34. In our limited population survey [Blasi et al., 2002], we did not detect this type of chromosome, showing that it is rare at least in the European population. However, we detected chromosomes carrying both $538(\mathrm{~T})$ and $545(\mathrm{~T})$ with a frequency of about 10\% [Blasi et al., 2002].

In order to check whether changes in the recently discovered exon 4B, which codes for an additional 13 amino acids, could be involved in disease pathogenesis, we sequenced genomic DNA surrounding this area from 35 patients (70 chromosomes) and found no changes.

TABLE 3. Summary of Disease-causing Mutations in ALDH5A1

\begin{tabular}{|c|c|c|c|c|c|}
\hline Exon & Type of mutation & Nucleotide change $^{a}$ & Change in protein & No. of families & No. of alleles \\
\hline 1 & Insertion & c.34dupG & p.A12fsX123 & 2 & 2 \\
\hline 1 & Deletion & c.103-121del $^{\mathrm{b}}$ & p.S35fsX49 & 1 & 1 \\
\hline 1 & Deletion & c.160_161delCT & p.S55fsX79 & 2 & 2 \\
\hline 1 & Nonsense & c.235C $>$ T & p.Q79X & 1 & 2 \\
\hline 1 & Missense & c.278G $>T$ & p.C93F & 3 & 4 \\
\hline 1 & Insertion & c.278_298dup & p.C93_R99dup & 1 & 1 \\
\hline Exon 2/Exon 5 & ? & r.EX2_EX5del & p.E119_K290del & 1 & 1 \\
\hline 2 & Nonsense & c.384C $>$ G & p.Y128X & 1 & 2 \\
\hline Exon 2/Intron 2 & Splice site & IVS2 + 1G $>$ A (r.sp1?) & ? & 1 & 1 \\
\hline 3 & Insertion & c.455_456 dupAG & p.A153fsX12 & 1 & 2 \\
\hline 3 & Deletion & c.460_473 del & p.H154fsX10 & 1 & 2 \\
\hline 3 & Missense & c.526G $>$ A & p.G176R & 2 & 3 \\
\hline 3 & Nonsense & c.574A $>$ T & p.K192X & 1 & 1 \\
\hline Intron $3 /$ Exon 4 & Splice site & IVS3 $-2 A>G(r .439-452 \mathrm{del})^{c}$ & p.K148fsX16 & 2 & 2 \\
\hline 4 & Nonsense & c. $612 \mathrm{G}>\mathrm{A}$ & p.W204X & 8 & 10 \\
\hline 4 & Deletion & c.621delC & p.S208fsX2 & 1 & 2 \\
\hline 4 & Missense & c.668G $>A$ & p.C223Y & 1 & 2 \\
\hline 4 & Missense & c. $698 \mathrm{C}>\mathrm{T}$ & p.T233M & 3 & 6 \\
\hline 5 & Missense & c.764A $>$ G & p.N255S & 1 & 1 \\
\hline 5 & Nonsense & c.781C $>$ T & p.R261X & 1 & 1 \\
\hline 5 & Missense & c. $803 \mathrm{G}>\mathrm{A}$ & p.G268E & 5 & 5 \\
\hline Exon 5/Intron 5 & Splice site & IVS5+1G $>A\left(\right.$ r.EX5del) ${ }^{c}$ & p.L243-K290del & 1 & 2 \\
\hline Exon 5/Intron 5 & Splice site & IVS5 + 1G $>$ T (r.EX5 del) ${ }^{c}$ & p.L243-K290del & 2 & 3 \\
\hline 6 & Missense & c. $1005 C>A$ & p.N335K & 1 & 1 \\
\hline Intron 6/Exon 7 & Splice site & IVS6 $-2 A>C$ (r.spl?) & ? & 1 & 1 \\
\hline 7 & Missense & c.1145C $>T$ & p.P382L & 1 & 1 \\
\hline 7 & Missense & c.1145C $>A$ & p.P382Q & 1 & 2 \\
\hline 8 & Missense & c. $1226 \mathrm{G}>\mathrm{A}$ & p.G409D & 6 & 9 \\
\hline 8 & Nonsense & c. $1234 \mathrm{C}>\mathrm{T}$ & p.R412X & 7 & 11 \\
\hline 8 & Insertion & c.1323 dup $G$ & p.P442fsX18 & 1 & 2 \\
\hline Exon 8/Intron 8 & Deletion & IVS8+1delG; IVS8+3A $>$ T (r.EX8del) ${ }^{c}$ & p.V392fsX10 & 2 & 4 \\
\hline Exon 9/Intron 9 & Splice site & IVS $9+1 G>T(r . E X 9 \mathrm{del})^{\mathrm{c}}$ & p.F449fsX53 & 5 & 10 \\
\hline 10 & Missense & c. $1460 \mathrm{~T}>\mathrm{A}^{\mathrm{b}}$ & p.V487E & 1 & 1 \\
\hline 10 & Nonsense & c.1540C $>$ T & p.R514X & 3 & 4 \\
\hline 10 & Missense & c.1597 G $>\mathbf{A}$ & p.G533R & 2 & 2 \\
\hline$?$ & & One allele not detected (see text) & & 2 & 2 \\
\hline
\end{tabular}

${ }^{a}$ Variants not published previously are in boldface. Nucleotides are numbered from the start codon with GenBank accession number Y11192 as reference.

${ }^{b}$ Published by Aoshima et al. [2002].

${ }^{\mathrm{c}}$ For splice site mutations the resulting change in RNA (as determined by sequencing RT-PCR product) is indicated when known. 
Nevertheless, preliminary evidence suggests that the relative expression level of the splice variant including exon $4 \mathrm{~B}$ could be variable, since it was undetectable in most of the sequenced RT-PCR products from patient material. However, in several cases it was visible as noise below the stronger signal of the normal sequence. Because it is likely that the splice variant lacks activity [Blasi et al., 2002], it is possible that a higher relative expression level of exon 4B contributes to disease pathology.

\section{Mutation Features}

In the current study we characterized 27 mutations in the ALDH5A1 gene that have not been reported before. The overall number of SSADH deficiencycausing mutations detected (including the eight mutations previously published) is now 35 . The spectrum of mutation includes five deletions at the genomic level, four insertions, seven splice site mutations (one of which is caused by a 1-bp deletion), seven nonsense, and 12 missense mutations. Overall, eight mutations cause a shift in the reading frame with premature truncation of the polypeptide (listed in Table 3, column 4) and three mutations cause an in-frame insertion or deletion. Of the 19 single nucleotide substitutions in the reading frame, 13 are transitions and 6 are transversions. Finally, in two instances the same nucleotide positions (IVS5 +1 and C1145) were the target of two mutational events.

\section{Expression Studies}

Eighteen different missense variants causing amino acid changes were identified among the SSADH patients (Tables 2 and 4). To establish which of these mutations were pathogenic, 16 mutant alleles were reproduced by site-directed mutagenesis and expressed in HEK 293 cells (Table 4). This analysis displayed two distinct groups of variants (high expression and low expression) with the exception of one allelic variant (N255S) that gave an intermediate expression level of $17 \%$. Nine of the mutations resulted in an almost complete loss of SSADH activity $(<5 \%)$ and can be considered causative for SSADH deficiency. Four of the mutant alleles detected during the course of this study cause a decrease in SSADH activity of less than 55\%, and their occurrence in the general European population has been reported elsewhere [Blasi et al., 2002]. These alleles can be considered to be nonpathogenic polymorphisms since carriers of SSADH deficiency do not have increased GHB levels in bodily fluids, nor do they display clinical symptoms even though SSADH activity is reduced to approximately 50\%. The silent D464D substitution (c.1398C > T) can also be included in the group of non-disease-causing mutations. Unlike the H180Y and P182L substitutions that were detected in the general population with a frequency of $23 \%$ and $7 \%$, respectively, the other substitutions (G36R and A237S) that did not strongly alter enzyme activity were not detected in controls [Blasi et al., 2002]. Because of the population
TABLE 4. SSADH Enzyme Activity of Mutant Protein Containing Missense Mutations Expressed in Mammalian Cells

\begin{tabular}{|c|c|c|}
\hline Nucleotide change(s) & Amino acid substitution(s) & SSADH activity $^{a}$ \\
\hline Control & - & $100 \%$ \\
\hline c. $106 \mathrm{G}>\mathrm{C}$ & p.G36R & $87 \%^{\mathrm{b}}$ \\
\hline c. $278 \mathrm{G}>\mathrm{T}$ & p.C93F & $3 \%$ \\
\hline c. $526 \mathrm{G}>\mathrm{A}$ & p.G176R & $<1 \%$ \\
\hline c. $538 \mathrm{C}>\mathrm{T}$ & p.H180Y & $83 \%^{\mathrm{b}}$ \\
\hline $\begin{array}{l}\text { c. } 538 \mathrm{C}>\mathrm{T}+ \\
\text { c. } 545 \mathrm{C}>\mathrm{T}\end{array}$ & $\begin{array}{l}\text { p.H180Y+ } \\
\text { p.P182L }\end{array}$ & $36 \%$ \\
\hline c. $538 \mathrm{C}>\mathrm{T}+$ & p.H180Y+ & $6 \%$ \\
\hline $\begin{array}{l}\text { c. } 545 \mathrm{C}>\mathrm{T}+ \\
\text { c. } 764 \mathrm{~A}>\mathrm{G}\end{array}$ & $\begin{array}{l}\text { p.P182L+ } \\
\text { p.N255S }\end{array}$ & \\
\hline c.545C $>\mathrm{T}$ & p.P182L & $48 \%^{b}$ \\
\hline c. $668 \mathrm{G}>\mathrm{A}$ & p.C223Y & $5 \%$ \\
\hline c. $698 \mathrm{C}>\mathrm{T}$ & p.T233M & $4 \%$ \\
\hline c.709G $>\mathrm{T}$ & p.A237S & $65 \%^{\mathrm{b}}$ \\
\hline c.764A $>$ G & p.N255S & $17 \%$ \\
\hline c. $803 \mathrm{G}>\mathrm{A}$ & p.G268E & $<1 \%$ \\
\hline c. $1005 \mathrm{C}>\mathrm{A}$ & p.N335K & $1 \%$ \\
\hline c. $1145 \mathrm{C}>\mathrm{T}$ & p.P382L & $2 \%$ \\
\hline c. $1145 \mathrm{C}>\mathrm{A}$ & p.P382Q & n.d. \\
\hline c. $1216 \mathrm{G}>\mathrm{A}$ & $\mathrm{p} . V 406 \mathrm{I}$ & n.d. \\
\hline c.1226G $>A$ & p.G409D & $<1 \%$ \\
\hline c. $1398 \mathrm{C}>\mathrm{T}$ & p.D464D & Not applicable \\
\hline c.1597G $>A$ & p.G533R & $<1 \%$ \\
\hline
\end{tabular}

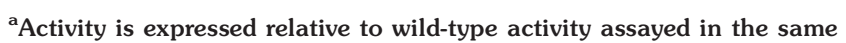
experiment.

${ }^{b}$ Published in Blasi et al. [2002].

n.d., not done.

association found between the H180Y and P182L polymorphisms we also expressed the composite variant. The effects of the two amino acid substitutions appear to be simply multiplicative, without any further synergistic effect. The finding of these sequence variants that have reduced, but still significant enzyme activity (36\% of the normal value if the two polymorphisms are combined) in our heterologous expression system may provide an explanation for the high variability in SSADH expression levels in healthy individuals [Gibson et al., 1991]. Because it is not currently known at what level of SSADH activity clinical symptoms arise we do not know whether the reduction of SSADH activity to $36 \%$ of the H180Y-P182L variant would cause clinical symptoms if the other allele is affected. Interestingly, two of the patients in whom the H180Y and P182L polymorphisms were detected (families 3 and 25) also shared the G36R substitution that affected activity in our expression system only slightly. Because the resulting amino-acid change lies in the mitochondrial leader sequence we collected the mitochondrial fraction from transfected cells and found that the activity was comparable to the wild-type activity (data not shown), showing that the mitochondrial targeting was not affected.

\section{DISCUSSION}

We analyzed the ALDH5A1 genotypes in a large cohort of patients with clinical and biochemical diagnosis of SSADH deficiency and report the characterization of 27 novel mutations in patients from 48 families not known to be related. This increases the total number of different mutations identified in 54 different families to 33 (Tables 2 and 3). Twenty of the mutations were sporadic and except for the IVS5 $+1 \mathrm{G}>\mathrm{A}$ allelic variant 
and the two alterations detected in the only Japanese SSADH patient currently known, all mutations reported previously were recurrent in this study.

The 10 missense mutations that were confirmed to be causative of SSADH deficiency by expression analysis were distributed rather randomly throughout the protein, except for a short stretch between aa 223-268 in which four of the deleterious amino-acid substitutions were located, accounting for $38 \%$ of the missense alleles detected (14 out of 37 missense alleles in a total of 10 families). These are encoded by exons 4 and 5 . Our observation then prompts to a higher priority in screening these two exons when searching for mutations in genomic material. The four altered residues between amino acids 223 and 268 were quite conserved between human aldehyde dehydrogenases and between SSADH proteins from the 26 different species of which the (putative) ALDH5A1 gene is sequenced, with the exception of the cysteine residue at position 223 that was mutated to a tyrosine in Patient 21. Surprisingly, all other human aldehyde dehydrogenases contain a tyrosine residue at this position. The importance of the cysteine at this position in SSADH is not only shown by the complete absence of activity of the C223Y mutant protein but is also suggested by the fact that 25 out of 26 (putative) SSADH proteins currently sequenced indeed contain a cysteine at this position. The six SSADH deficiency-causing missense mutations located outside the area from aa 223-268 were also quite conserved between human aldehyde dehydrogenases and between different SSADH proteins with the exception of the C93F and G533R mutations. On the other hand, the five nonpathogenic variants targeted nonconserved residues with the exception of the highly conserved alanine 237.

Only one of the missense mutations (N335K) was found in close proximity to the active site glutamate and cysteine residues (E306 and C340, as predicted by the Prosite signature motifs of aldehyde dehydrogenases). In contrast, among the 26 missense mutations in ALDH3A2 responsible for Sjögren-Larsson syndrome, eight were found near the active site (between aa 283 and 365 ) and not a single mutation was found between aa 223 and 268 where most ALDH5A1 mutations were identified (numbers refer to positions in the SSADH protein after aligning the sequences) [De Laurenzi et al., 1996; Sillen et al., 1998; Rizzo et al., 1999; Willemsen et al., 2001]. Four of the ALDH3A2 mutations were detected near the C-terminus (leucine 535 in SSADH) where also the G533R mutation detected in Patients 7 and 42 are located. It is not known whether the G533K substitution in SSADH affects the stability and/or the activity of the protein, but it is interesting to note that a E487K substitution at 11 amino acids distance from the c-terminus of ALDH2 (mitochondrial aldehyde dehydrogenase) increases the turnover and reduces the activity of the enzyme in a dominant fashion [Xiao et al., 1996]. The E487K mutation is a polymorphism found in approximately $50 \%$ of the Oriental population that causes alcohol-induced flushing resulting from acetaldehyde accumulation after alcohol consumption.

Because of the limited availability of clinical data and the low number of patients with identical haplotypes, discussing genotype-phenotype relations is rather premature. One family with an unusual clinical presentation (Family 3) [Gibson et al., 1997b] was included in the current study and was shown to have a complex combination of mutations and polymorphisms, but the fact that one of the mutations was a nonsense mutation argues against the assumption that residual activity might have influenced the clinical manifestations.

Although missense mutations were detected in 20 different families, the observation that only one of these mutations (N255S) has an intermediate effect on the activity of the enzyme activity in our expression system suggests that differences in residual enzyme activity play a very limited role in determining the severity of the disease. This mutation was found in a patient with a complex genotype (Family 25 in Table 2). When expressed, this mutation produced a six-fold reduction of activity (from 100\% to 17\%). In combination with the H180Y and P182L polymorphisms the activity was further reduced to $6 \%$. It is worth noting that the genotype of this patient is compatible with both arrangements. If the patient actually carried the N255S mutation on a H180Y-P182L background the 6\% residual activity could easily explain SSADH deficiency (assuming heterozygosity with another yet unknown mutation). An alternative explanation would be that the N255S mutant form of the protein cannot form active heterotetramers with the H180Y-P182L variant. This would be rather similar to the dominant-negative effect that the polymorphism in the ALDH2 gene has on protein activity [Xiao et al., 1996]. Unfortunately samples from parents or siblings were not available and we were therefore unable to determine the haplotype with certainty.

There are many factors that could influence the clinical features in patients. There is no correlation between GHB levels in physiological fluids and the severity of the disease, yet the heterogeneity in clinical presentation in sibships is less extensive than between unrelated patients [Gibson et al., 1998]. Factors that could potentially cause modulation of the clinical phenotype are polymorphisms in other metabolic enzymes affecting GABA metabolism, differences in the activity of other aldehyde dehydrogenases that have an overlapping substrate specificity, a different rate of formation of $\mathrm{GHB}$ from succinate semialdehyde or different concentrations of succinate semialdehyde in the brain. Altered expression of GABA and GHB receptors might also contribute to pathogenesis [Mehta et al., 2002]. SSADH may also play a role in the oxidation and removal of other toxic aldehydes in brain, such as 4-hydroxy-2-nonenal [Picklo et al., 2001a, b]; this observation would be supported by the significant decrease in brain reduced glutathione (GSH) that we have detected in the brain of Aldh5a1 knockout mice (unpublished results). A recent report about an SSADH 
patient who developed malignant neuroleptic syndrome after a single dose of haloperidol suggests that SSADH deficiency could affect other metabolic pathways as well [Neu et al., 2002].

The GABA shunt is also active in most peripheral organs, but not much is known about its function. In plants, SSADH may be involved in regulation of cytosolic $\mathrm{pH}$ and adaptation to stress. The observation that Arabidopsis SSADH (which is 58\% identical and $74 \%$ homologous to human SSADH) is inhibited by high $\mathrm{NADH} / \mathrm{NAD}^{+}$ratios suggests that the supply of succinate to the Krebs cycle is affected by the reduction potential in the mitochondria [Busch and Fromm, 1999]. Whether these (potential) additional functions of SSADH activity in peripheral organs are involved in disease pathogenesis is currently not known. The recent development of a mouse model for SSADH deficiency provides a valuable tool for studying the neurophysiological consequences of SSADH on various other metabolic pathways, and will hopefully aid in finding modifier genes and other factors affecting disease pathogenesis [Hogema et al., 2001b; Gibson et al., 2002].

\section{ACKNOWLEDGMENTS}

We thank Henry Senephansiri, Melissa Taylor, and Maneesh Gupta for technical assistance and data analysis at the Oregon Health and Sciences University, and Efraim Rosenberg, Dana Bunea, and Silvy van Dooren for their assistance at the VU University Medical Center, The Netherlands. We thank Dr. J. Berthelot (France); Dr. G. Besley, Dr. M. Cleary, Dr. D. Isherwood (UK); Dr. M. Coker (Turkey); Dr. I. Kolbe, Dr. L. Klinge, Dr. D. Hunneman, Dr. U.A. Mau, Dr. Ch. Spaich, Prof. Dr. F. Aksu (Germany); and Prof. G. Pescia (Switzerland) for sending patient materials. This work was supported by grants from Telethon Onlus Italia (E.818 to P.M.) and March of Dimes National Birth Defects Foundation (1-FY00-352 to K.M.G.). Patrizia Malaspina is a CNR Short Mobility Fellow.

\section{REFERENCES}

Aligianis IA, Farndon PA, Gray RG, Heath SK, Kilby M, Gibson KM, Akaboshi S. 2002. Prenatal diagnosis of succinate semialdehyde dehydrogenase deficiency in non-identical twins. J Inherit Metab Dis 25:517-518.

Aoshima T, Kajita M, Sekido Y, Ishiguro Y, Tsuge I, Kimura M, Yamaguchi S, Watanabe K, Shimokata K, Niwa T. 2002. Mutation analysis in a patient with succinic semialdehyde dehydrogenase deficiency: a compound heterozygote with 103. 121del and $1460 \mathrm{~T}>\mathrm{A}$ of the ALDH5A1 gene. Hum Hered 53:42-44.

Blasi P, Pilo Boyl P, Ledda M, Novelletto A, Gibson KM, Jakobs C, Hogema BM, Akaboshi S, Loreni F, Malaspina P. 2002. Structure of human succinic semialdehyde dehydrogenase gene: identification of promoter region and alternatively processed isoforms. Mol Genet Metab 76:348-362.

Busch KB, Fromm H. 1999. Plant succinic semialdehyde dehydrogenase. Cloning, purification, localization in mitochon- dria, and regulation by adenine nucleotides. Plant Physiol 121:589-597.

Cash CD, Maitre M, Mandel P. 1979. Purification from human brain and some properties of two NADPH-linked aldehyde reductases which reduce succinic semialdehyde to 4-hydroxybutyrate. J Neurochem 33:1169-1175.

Chambliss KL, Caudle DL, Hinson DD, Moomaw CR, Slaughter CA, Jakobs C, Gibson KM. 1995. Molecular cloning of the mature $\mathrm{NAD}(+)$-dependent succinic semialdehyde dehydrogenase from rat and human. cDNA isolation, evolutionary homology, and tissue expression. J Biol Chem 270: 461-467.

Chambliss KL, Hinson DD, Trettel F, Malaspina P, Novelletto A, Jakobs C, Gibson KM. 1998. Two exon-skipping mutations as the molecular basis of succinic semialdehyde dehydrogenase deficiency (4-hydroxybutyric aciduria). Am J Hum Genet 63:399-408.

De Laurenzi V, Rogers GR, Hamrock DJ, Marekov LN, Steinert PM, Compton JG, Markova N, Rizzo WB. 1996. Sjögren-Larsson syndrome is caused by mutations in the fatty aldehyde dehydrogenase gene. Nat Genet 12:52-57.

De Vivo DC, Gibson KM, Resor LD, Steinschneider M, Aramaki S, Cote L. 1988. 4-hydroxybutyric acidemia: clinical features, pathogenetic mechanisms, and treatment strategies. Ann Neurol 24:304.

den Dunnen JT, Antonarakis SE. 2000. Mutation nomenclature extensions and suggestions to describe complex mutations: a discussion. Hum Mutat 15:7-12.

Gibson KM, Hoffmann G, Nyhan WL, Aramaki S, Thompson JA, Goodman SI, Johnson DA, Fife RR. 1988. 4-hydroxybutyric aciduria in a patient without ataxia or convulsions. Eur J Pediatr 147:529-531.

Gibson KM, Goodman SI, Frerman FE, Glasgow AM. 1989. Succinic semialdehyde dehydrogenase deficiency associated with combined 4-hydroxybutyric and dicarboxylic acidurias: potential for clinical misdiagnosis based on urinary organic acid profiling. J Pediatr 114:607-610.

Gibson KM, Aramaki S, Sweetman L, Nyhan WL, DeVivo DC, Hodson AK, Jakobs C. 1990. Stable isotope dilution analysis of 4-hydroxybutyric acid: an accurate method for quantification in physiological fluids and the prenatal diagnosis of 4-hydroxybutyric aciduria. Biomed Environ Mass Spectrom 19:89-93.

Gibson KM, Lee CF, Chambliss KL, Kamali V, Francois B, Jaeken J, Jakobs C. 1991. 4-hydroxybutyric aciduria: application of a fluorometric assay to the determination of succinic semialdehyde dehydrogenase activity in extracts of cultured human lymphoblasts. Clin Chim Acta 196:219-221.

Gibson KM, Baumann C, Ogier H, Rossier E, Vollmer B, Jakobs C. 1994. Pre- and postnatal diagnosis of succinic semialdehyde dehydrogenase deficiency using enzyme and metabolite assays. J Inherit Metab Dis 17:732-737.

Gibson KM, Christensen E, Jakobs C, Fowler B, Clarke MA, Hammersen G, Raab K, Kobori J, Moosa A, Vollmer B, Rossier E, Iafolla AK, Matern D, Brouwer OF, Finkelstein J, Aksu F, Weber HP, Bakkeren JA, Gabreels FJ, Bluestone D, Barron TF, Beauvais P, Rabier D, Santos C, Lehnert W. 1997a. The clinical phenotype of succinic semialdehyde dehydrogenase deficiency (4-hydroxybutyric aciduria): case reports of 23 new patients. Pediatrics 99:567-574.

Gibson KM, Doskey AE, Rabier D, Jakobs C, Morlat C. 1997b. Differing clinical presentation of succinic semialdehyde dehy- 
drogenase deficiency in adolescent siblings from Lifu Island, New Caledonia. J Inherit Metab Dis 20:370-374.

Gibson KM, Hoffmann GF, Hodson AK, Bottiglieri T, Jakobs C. 1998. 4-hydroxybutyric acid and the clinical phenotype of succinic semialdehyde dehydrogenase deficiency, an inborn error of GABA metabolism. Neuropediatrics 29:14-22.

Gibson KM, Jakobs C. 2001. Disorders of beta- and gammaamino acids in free and peptide-linked forms. In: Scriver CR, Beaudet AL, Valle D, Sly WS, editors. The metabolic basis of inherited disease. 8th edition. New York: McGraw-Hill. p 2079-2105.

Gibson KM, Schor DS, Gupta M, Guerand WS, Senephansiri H, Burlingame TG, Bartels H, Hogema BM, Bottiglieri T, Froestl W, Snead OC, Grompe M, Jakobs C. 2002. Focal neurometabolic alterations in mice deficient for succinate semialdehyde dehydrogenase. J Neurochem 81:71-79.

Hodson AK, Gibson KM, Jakobs C. 1990. Developmental resolution of ataxia in succinic semialdehyde dehydrogenase deficiency. Ann Neurol 28:438.

Hogema BM, Akaboshi S, Taylor M, Salomons GS, Jakobs C, Schutgens RB, Wilcken B, Worthington S, Maropoulos G, Grompe M, Gibson KM. 2001a. Prenatal diagnosis of succinic semialdehyde dehydrogenase deficiency: increased accuracy employing DNA, enzyme, and metabolite analyses. Mol Genet Metab 72:218-222.

Hogema BM, Gupta M, Senephansiri H, Burlingame TG, Taylor M, Jakobs C, Schutgens RB, Froestl W, Snead OC, Diaz-Arrastia R, Bottiglieri T, Grompe M, Gibson KM. 2001b. Pharmacologic rescue of lethal seizures in mice deficient in succinate semialdehyde dehydrogenase. Nat Genet 29: 212-216.

Jakobs C, Bojasch M, Monch E, Rating D, Siemes H, Hanefeld F. 1981. Urinary excretion of gamma-hydroxybutyric acid in a patient with neurological abnormalities. The probability of a new inborn error of metabolism. Clin Chim Acta 111:169-178.

Jakobs C, Smit LM, Kneer J, Michael T, Gibson KM. 1990. The first adult case with 4-hydroxybutyric aciduria. J Inherit Metab Dis $13: 341-344$.
Mason PE, Kerns WP, 2nd. 2002. Gamma hydroxybutyric acid (GHB) intoxication. Acad Emerg Med 9:730-739.

Mehta AK, Gupta M, Gibson KM, K TM. 2002. Decreased GHB and GABA receptor binding in succinate semialdehyde dehydrogenase (SSADH:Aldh5a1) deficient mouse brain. Program No. 431.415. Abstract Viewer/Itinerary Planner. Online. Washington, DC: Society for Neuroscience. www.sfn.org

Neu P, Seyfert S, Brockmoller J, Dettling M, Marx P. 2002. Neuroleptic malignant syndrome in a patient with succinic semialdehyde dehydrogenase deficiency. Pharmacopsychiatry 35:26-28.

Picklo MJ, Olson SJ, Markesbery WR, Montine TJ. 2001a. Expression and activities of aldo-keto oxidoreductases in Alzheimer disease. J Neuropathol Exp Neurol 60:686-695.

Picklo MJ Sr, Olson SJ, Hayes JD, Markesbery WR, Montine TJ. 2001b. Elevation of AKR7A2 (succinic semialdehyde reductase) in neurodegenerative disease. Brain Res 916:229-238.

Rizzo WB, Carney G, Lin Z. 1999. The molecular basis of SjögrenLarsson syndrome: mutation analysis of the fatty aldehyde dehydrogenase gene. Am J Hum Genet 65:1547-1560.

Sillen A, Anton-Lamprecht I, Braun-Quentin C, Kraus CS, Sayli BS, Ayuso C, Jagell S, Kuster W, Wadelius C. 1998. Spectrum of mutations and sequence variants in the FALDH gene in patients with Sjögren-Larsson syndrome. Hum Mutat 12: 377-384.

Trettel F, Malaspina P, Jodice C, Novelletto A, Slaughter CA, Caudle DL, Hinson DD, Chambliss KL, Gibson KM. 1997. Human succinic semialdehyde dehydrogenase. Molecular cloning and chromosomal localization. Adv Exp Med Biol 414:253-260.

Willemsen MA, L IJ, Steijlen PM, Rotteveel JJ, de Jong JG, van Domburg PH, Mayatepek E, Gabreels FJ, Wanders RJ. 2001. Clinical, biochemical and molecular genetic characteristics of 19 patients with the Sjögren-Larsson syndrome. Brain 124:1426-1437.

Xiao Q, Weiner H, Crabb DW. 1996. The mutation in the mitochondrial aldehyde dehydrogenase (ALDH2) gene responsible for alcohol-induced flushing increases turnover of the enzyme tetramers in a dominant fashion. J Clin Invest 98:2027-2032. 